\title{
Orbital dimensions of Maharashtrian population a direct measurement study using dry skulls
}

\author{
Shaikh Amjad', Zuberi Hussain Riyaz ${ }^{2 *}$, Azhar Ahmed Siddiqui ${ }^{3}$, MD Kalim Ansari ${ }^{4}$ \\ ${ }^{1,4}$ Assistant Professor, ${ }^{2}$ Associate Professor, ${ }^{3}$ Professor and HOD, ${ }^{1}$ Dept. of Dentistry, ${ }^{2,3}$ Dept. of Anatomy, ${ }^{4}$ Dept. of Oral \\ and Maxillofacial Surgery, ${ }^{\mathbf{1}} \mathbf{J}$ JIIUs Indian Institute of Medical Science and Research, Jalna, Maharashtra, Aligarh Muslim \\ University, Aligarh, Uttar Pradesh, India
}

*Corresponding Author: Zuberi Hussain Riyaz

Email: zuberihussain@gmail.com

\begin{abstract}
Introduction: Anatomy of Human Orbit is complex, which plays main character in the assessment of craniofacial complex. The bony orbit which lodges the Eye ball is significant not only for anatomists but also for oral and maxillofacial surgeons, forensic experts, ophthalmic surgeon, and Neurosurgeon. The main objectives of the existent study to specify the common location orbital parameters of the Maharashtrian population.

Materials and Methods: 31 dry human skulls were taken for observational study from department of anatomy IIMSR Warudi, Badnapur. All skulls were adult type. The exact age and sexes of the skulls were not known. Those were used for tutorial teaching for medical students.

Measurements: The measurements for dimension of orbital cavities were taken with the help of manual Vernier Caliper.

Orbital Length: This indicates distance between superior and inferior margin of orbital fossa.

Orbital Breadth: Distance between medial and lateral walls of orbital fossa (from frontal process of zygomatic arch to frontal process of maxilla.

Orbital Index: Calculated as Orbital length/Orbital Breadth X 100. Measurements were recorded and expressed as Mean \pm Standard Deviation and range (Min. value - Max. value of each measurement).

Results: The results indicate that right orbital length displayed $(33.70 \pm 1.20 \mathrm{~mm})$ and right orbital Breadth exhibited $(38.90 \pm 2.20 \mathrm{~mm})$. From these consequences, orbital index was estimated as orbital length/Orbital breadth x 100. A mean orbital index of right side $86.63 \mathrm{~mm}$ and left side $85.99 \mathrm{~mm}$ was deduced (Table 1). The assessment of figures from pair of orbits by paired t test shows statistically significant difference in orbital length $(\mathrm{p}=0.021)$ and orbital index $(\mathrm{p}=0.011)$. Whereas, Orbital breadth has not shown statistically significant difference $(\mathrm{p}=0.25)$.

Conclusion: This study specifies valuable reference orbital morphometric facts of Maharashtrian population, which are very significant throughout the Maxillofacial Plastic surgery, neurosurgery forensic research and Ophthalmological procedures.
\end{abstract}

Keywords: Dry skull, Orbital dimensions, Orbital index.

\section{Introduction}

Orbital base is avital feature in Norma frontalis. It situated between neurocranium and splanchnocranium bilateral to the nasal root. It specifies safety, spatial connection between two eyeballs and preserves appropriate positioning of visual axis which is important for conjugate eye movements and binocular vision. ${ }^{1}$ Hollow bony cavities in the facial skeleton the orbits lodges and protect the eyeballs and accessory visual structures. $^{2}$ Anatomical structural Knowledge, proportion, and mechanical function of the human body and racial dissimilarities in ocular anatomy is important to clinical evaluation and management of patients. ${ }^{3}$ Supporting this structural character of human body has been supported by innovations in medical imaging technology such as ultrasonography, radiography, CT
Scan and MRI. In addition, anthropometry, which correspondingly assists understanding of anatomical structures, creates system of stating quantitatively the form of human body and skeleton. It is an essential device of living anthropology and has been of enormous benefit in expansion of forensic sciences in general and forensic medicine in certain. Anthropometric findings are an essential part of craniofacial surgery and syndromology. ${ }^{4}$ Due to this explanation, standards based on ethnic or racial information are necessary since these values suggest possibly various shapes of craniofacial expansion subsequent from ethnic, racial and sexual variances. $^{5}$

Patnaik et $\mathrm{al}^{6}$ revealed that in each orbital cavity, width is normally greater than height, relative between two is given by orbital index, which varies in different 
races (Orbital Index= Orbital length/Orbital Breadth). Taking orbital index as the standard, three classes of orbits have been defined.

Megaseme (Large) - The Orbital index is 89 or over. This type is seen in yellow races ${ }^{7}$

Mesoseme (Intermediate) - The orbital index ranges between 89 to 83 . This type is seen in the white races. ${ }^{8}$

Microseme (Small) - Orbital index 83 or less. This type is distinguishing of black races where the orbital opening is rectangular. ${ }^{7}$

The study was designed with an aim to gather anthropometrical information in Indian population and equate it with other earlier analyses conducted in same and various race. The mean, standard deviation and range was analyzed from data. Moreover, these analyses will give a hidden insight in morphological character of anatomic relations of orbit and additionally directing standard for Maxillofacial surgeons who are involved in there constructive management of fractures due to traumas and various orbital pathologies.

\section{Materials and Methods}

31 dry human skulls were taken for observation from department of anatomy IIMSR Warudi, Badnapur. All skulls were adult type. The exact age and sexes of the skulls were not known. They were used for tutorial teaching for medical students.

Measurements: The measurements for extents of orbital cavities were noted with the help of manual Vernier Caliper.

Orbital length: This refers to distance between superior and inferior margin of orbital fossa (Fig.1).

Orbital breadth: The distance between medial and lateral walls of orbital fossa (from frontal process of zygomatic arch to frontal process of maxilla. (Fig. 1)

Orbital index: Calculated as Orbital length/Orbital Breadth X 100.Dimensions were documented as a Means \pm Standard Deviation and range (Min. value Max. value of each measurement).

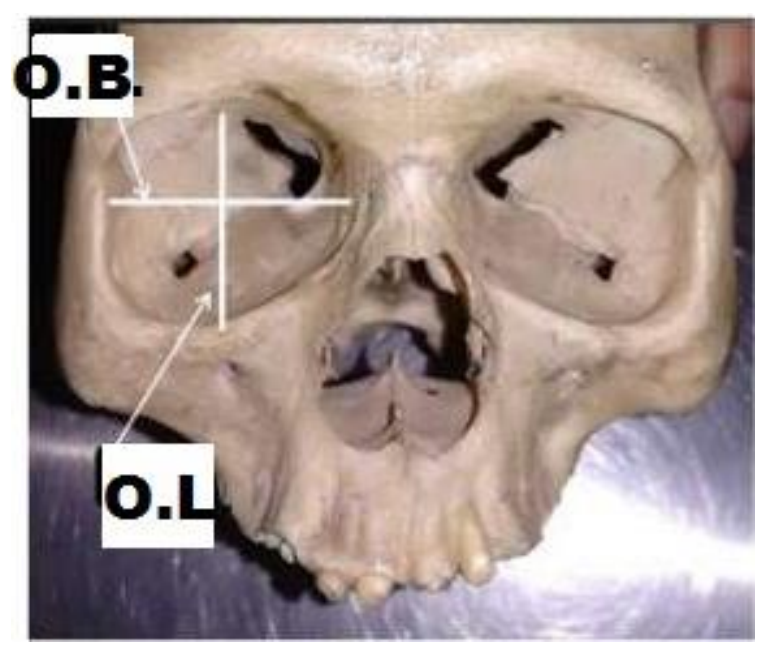

Fig. 1: Showing Orbital length (OL) and Orbital Breadth (OB).

\section{Results}

Table 1: Showing the descriptive statistics of the orbital dimensions

\begin{tabular}{|l|c|c|c|}
\hline Parameter & Orbit & $\begin{array}{c}\text { Mean } \pm \\
\text { SD(mm) }\end{array}$ & P-value \\
\hline \multirow{2}{*}{ Orbital length } & Right & $33.70 \pm 1.20$ & 0.021 \\
\cline { 2 - 3 } & Left & $32.23 \pm 2.02$ & \\
\hline Orbital & Right & $38.90 \pm 2.20$ & 0.25 \\
\cline { 2 - 3 } Breadth & Left & $37.48 \pm 3.19$ & \\
\hline Orbital index & Right & $86.63 \pm 2.17$ & 0.011 \\
\cline { 2 - 3 } & Left & $85.99 \pm 2.02$ & \\
\hline \multirow{2}{|l|}{$\begin{array}{l}\text { SD= Standard deviation, } \\
\text { p-value =Significance between bilateral side orbits. }\end{array}$} \\
\hline
\end{tabular}

The results indicate that the right orbital length showed $(33.70 \pm 1.20 \mathrm{~mm})$ and left orbital length is (32.23 $\pm 2.02)$. Whereas, right orbital Breadth showed (38.90 \pm $2.20 \mathrm{~mm})$ and left orbital Breadth $(37.48 \pm 3.19)$. From the results, orbital index was calculated as orbital length/Orbital breadth x 100. A mean orbital index of right side $83.97 \mathrm{~mm}$ and left side $85.99 \mathrm{~mm}$ was deduced (Table 1). The contrast of numbers from pair of orbits by paired $t$ test indicates significant difference in orbital length $(\mathrm{p}=0.021)$ and orbital index $(\mathrm{p}=0.011)$. But Orbital breadth has not shown significant difference $(\mathrm{p}=0.25)$.

\section{Discussion}

Morphometric parameters of orbit are vital in oral and maxillofacial surgery, Neurosurgery and Ophthalmology. Orbital index has importance to define sex of person in forensic science. Information of these parameters is 
essential to their effective use subsequently they are various from one population to another. Outcomes from our study are compared to earlier analyses. In our study, bilateral orbits revealed significant variance in orbital index ( $\mathrm{p}$ value $=0.011)$ and in orbital length ( $\mathrm{p}$ value $=0.021)$, but difference was not significant for the orbital breadth $(\mathrm{p}=0.25)$. This corresponds with earlier analysis (Kaur et al and Gosavi S.N et al) ${ }^{9}$ which exhibited that the Indian races have microseme orbital index. The Orbital index which defines shape of face varies in different population groups. This means that orbit with larger width than height will have smaller orbital parameters although persons with larger orbital index has narrow faces. ${ }^{10}$ Anthropometric analyses are an essential part of living variability, ${ }^{11,12}$ forensic examination, ${ }^{13}$ craniofacial surgery and syndromology. ${ }^{14}$ Orbital indices are essential measurements for evaluation, and identification of craniofacial syndromes and post traumatic malformations. The awareness of orbital index of a specific area can be used as parameters for additional findings and management of craniofacial deformed patients. ${ }^{15}$ Differences in orbital index in various races and are as support that craniofacial development depends on ethnic, races, social and dietary background. The sizes of orbital base, orbit and skull are useful in the following aspects.

1. Primary finding of orbital pathology. ${ }^{16}$ Modifications or irregular widening of orbital dimensions will be consequences by bone lesion or expansion in intraorbital pressure. It is speedy in child (13 months), and outcomes in irregularity in orbital dimensions with loss or bone damage. E.g. Tumors of lacrimal gland or benign and malignant tumors of orbit.

2. Traumatic disorders ${ }^{1}$ : Fracture of orbital Floor or Orbital walls disturbs sight. It might produce strabismusor squints, diplopia (double vision) by affecting binocular vision and conjugate movements of eyeball. Fractures in middle third or upper third of face will disturb orbit or its margins. Fracture of maxilla or frontal bone will destruction of oblique muscles of eye.

3. Inherited disorders: Imperfect orbit is main feature in Mandibulofacial dysostosis ${ }^{1}$ (Treacher Collins syndrome) which is genetic abnormalities of facial growth produced by haplo-insufficiency of gene TCOF1. Dimensions and shape of orbit provides idea about degree of irregularity.
4. In designing and determining size of bridge and frame of spectacle and of protecting instrument for eye. $^{17}$

5. In cranial or orbital reconstruction cosmetic surgeries ${ }^{18}$ and to preventoperatingproblems. ${ }^{19}$

6. The biological and personal character of persons. ${ }^{1}$ (e.g. sex, race, age).

7. Facial estimate (reconstruction) to found individual character throughout forensic study.

\section{Clinical significance}

Analysis on extents of orbit is significant in anatomy, oral and maxillofacial surgery, anthropology, forensic science,${ }^{20}$ throughout reconstruction surgery ${ }^{21}$ of orbit and cranium and to prevent neurovascular injury. It is necessary for aiming bridge and frame of spectacle and protecting instrument for eye and head.

\section{Conclusion}

Morphometric data of Maharashtrian population, which are extremely significant throughout maxillofacial surgery, plastic surgery, and neurosurgeries and also in the plan of eye protecting Instrument. In addition, these parameters particularly Orbital index can be usage throughout anthropological and forensic investigation of unknown persons for defining gender, ethnicity.

\section{Source of funding}

None.

\section{Conflict of interest}

None.

\section{References}

1. Standring S. Gray's Anatomy, The anatomical basis of clinical practice, 41 th edition. Churchill livingstone, Elsevier. 2012.

2. Moore KL. Clinical Oriented Anatomy 6th Ed. Lippincott William and Wilkins, 2014; 7:889-90.

3. Fawehinmi HB, Ligha AE, Chikwu P Orbital Dimensions of Nigerian Adults. Jobiomed Afr 2008;6:1-2.

4. Novit M. Facial, upper facial, and orbital index in Batak, Klaten, and Floresstudents of Jember University. Dent $J$ (Maj.Ked.Gigi). 2006;39(3):116-9.

5. Evereklioglu C, Doganay S, Er H, Gunduz A, Tercan M, Balat A, Cumurcu T. Craniofacial anthropometry in a Turkish population. Clef Palate-Craniofac $J$ 2002;39(2):208-18. 
6. Patnaik V.V.G., BalaSangu, SinglaRajan K. Anatomy of the Bony Orbit- Some Applied Aspects. J Anat Soc India 2001;50(1):59-67.

7. Cassidy PJ. "Megaseme" Webster dictionary. Answer. Com (homepage on internet), 1913; Retrieved from http:/www.answer.com/topic/megaseme.

8. Mcgraw Hill, dictionary of scientific and technical terms "mesoconch" Mcgraw hill company Inc, answer.com (homepage on the internet) 2003; Retrieved from http:/www.answer.com/topic/mesoconch.

9. Gosavi S N, Jadhav S D, Zambre B R. A study of orbital morphometry in Indian dry skulls. Asian J Biomed Pharm Sci 2014;04(29):23-25.

10. Kaur J, Yadav S, Sing Z. Orbital dimentions - A direct measurement study using dry skulls. J Acad Indus Res 2012;1(6):293-5.

11. Krishan K. Determination of stature from foot and its segments in a North Indian population. Am J Forensic Med Pathol 2008;29(4):297-303.

12. Krishan K. Estimation of stature from footprint and foot outline dimensions in Gujjars of North India. Forensic Sci Int 2008;175(2-3):93-101.

13. Krishan K. Establishing correlation of footprints with body weight--forensic aspects. Forensic Sci Int 2008;179(1):6396.

14. Krishan K. Anthropometry in Forensic Medicine and Forensic Science-'Forensic Anthropometry'. Int J Forensic Sci 2007;2(1).
15. Farkas L. G, Posnick J. C, Hreezko T. M, Pron G. E. Anthropometric growth study of the head. Cleft Palate Craniofac J 1992;29:303-8.

16. Evereklioglu C, Dogany S, Er H, Gunduz A, Tercan M, Balat A. (2002). Craniofacial anthropometry in a Turkish population. Cleft Palate Craniofac J 2002;39(2):208-18.

17. Moreiras JVP, Preda MC, Pumar JM, Orbit. Examination, Diagnosis, Microsurgery, Pathology.vol-1. Highlights of ophthalmology internationalcity knowledge, panama. English edition 2004;73-4.

18. Weaver AA, Loftis KI, Tan JC, Duma SM, Stitzel JD. CT scan based three-dimensional measurement of orbit and eye anthropometry. IOVS 2010;51(10):4892-7.

19. Munguti J, Mandela P, Butt F; Referencing orbital measures for surgical and cosmetic procedures. Ant J Afr 2012;1(1):40-5.

20. Ebeye OA, Otikpo O. Orbital Index in Urhobos of Nigeria. IOSR J Dent Med Sci 2013;8(2):51-3.

21. Fetouh FA, Mandour D. Morphometric analysis of the orbit in adult Egyptian skulls and its surgical relevance. Eur $J$ Anat 2014;18(4):303-15.

How to cite this article: Amjad S, Riyaz ZH, Siddiqui AA, Ansari MDK. Orbital dimensions of Maharashtrian population a direct measurement study using dry skulls. Int Dent J Student Res 2019;7(4):103-6. 